\title{
THE ANALYSIS OF THERMAL SENSATION VOTE ON THE COMFORT OF OCCUPANTS OF VERNACULAR HOUSES IN MOUNTAINOUS AREAS OF WONOSOBO, INDONESIA
}

\author{
Hermawan $^{1 *}$, Eddy Prianto $^{2}$ and Erni Setyowati ${ }^{3}$ \\ ${ }^{1}$ Architecture Department, Qur'anic Science University, Indonesia \\ ${ }^{2}$ Architecture Department, Diponegoro University, Indonesia \\ ${ }^{3}$ Architecture Department, Diponegoro University, Indonesia \\ ${ }^{1}$ hermawanarsit@gmail.com, ${ }^{2}$ dr.eddyprianto@yahoo.fr, ${ }^{3}$ ernisyahdu@gmail.com
}

\begin{abstract}
Thermal Sensation Vote (TSV) is an instrument which is believed to present as a basis to analyze thermal adaptive comfort. TSV is also used to determine the thermal adaptive comfort based on environmental and personal thermal conditions. The difference of the thermal environment is found in houses located in mountainous areas. Exposed stone houses and those with wooden walls belong to vernacular houses in mountainous areas. The present study aims at comparing Thermal Sensation Vote (TSV) of occupants of exposed stone houses and those of wooden houses. Subjective data were collected through 7-pint scales thermal sensation in a year on four seasonal periods: the beginning of the wet season, the middle of the wet season, the beginning of the dry season, and the middle of the dry season. A survey was conducted in 5 days for each seasonal period. The data were collected four times a day: in the morning, afternoon, evening, and at night. The collected data were then tabulated and converted to a percentage. Afterward, the data were processed using bar diagrams and described through descriptive narration. The results of the study indicate that the age and gender of the occupants determine the thermal sensation being felt. Exposed stone houses are proved to give comfort to occupants living in mountainous areas.
\end{abstract}

Keywords - Thermal Sensation Vote, Questionnaire, Mountainous Areas

\section{INTRODUCTION}

One of the challenges for engineers in designing an indoor environment is combining the need for energy efficiency and occupant comfort [1]. Thermal comfort belongs to one of the occupant comforts which exerts an influence on the energy efficiency. The thermal comfort falls into two categories: static thermal comfort and thermal adaptive comfort. The former is developed from laboratory tests and is based on Predicted Mean Vote (PMV), while the latter is developed from field tests and is based on Thermal Sensation Vote (TSV). The results of both differ in analyzing thermal comfort [2].

TSV presents as occupants' response on thermal variations in a certain area [3]. Seven items for thermal sensation used in thermal comfort studies refer to ASHRAE's which include +3 (very hot), +2 (hot), +1 (warm), 0 (neutral), -1 (slightly cool), -2 (cold), -3 (very cold). Thermal adaptive comfort serves as a basis for the establishment of such international

Received: May 10, 2019

Reviewed: August 21, 2019

Accepted: August 27, 2019

* Corresponding Author 
standards as EN 16798 and ASHRAE 55-2017. Both standards are used in the basic analysis of thermal studies. One of the studies was carried out in Chile, resulting in a novel thermal adaptive comfort model [4].

When responding to the environment, different individuals have different thermal sensation characteristics. However, all of the individuals share similar trends in giving a response to the environment. TSV should be analyzed in each different individual to find out the thermal adaptive comfort model which fits him/her [5]. TSV is believed to be able to predict human responses on thermal comfort. TSV is further developed for such detailed thing as Seasonal Thermal Sensation Vote (S-TSV). The thermal sensation used is similar to that used in studies on TSV, i.e. ASHRAE 7-point scales, but the time of the day used to in analysis is more detailed in the afternoon and in the evening [6].

Besides the former studies that evaluated either physiological or psychological effects of the environment in a room, another study investigated thermal sensation effects on individual emotional responses [7]. TSV can be a reliable instrument for various studies related to human responses. To indicate occupant responses, TSV is closely related to occupant clothing items and activities [8]. The occupant clothing items and activities are factors which exert an influence on TSV in addition to climate.

The climate of a region will contribute to different occupant responses. Occupants receive thermal more easily in a cold climate [9]. Besides regional differences, seasonal differences in the same region will also influence occupant responses. A study conducted on four different seasons demonstrated different occupant responses [10]. The different occupant responses in different seasons result in the difference in the formulation of thermal adaptive comfort prediction model which enables to predict human responses in addressing their thermal environment in each different season [11]. Cold climate occurs in mountainous locations. In tropical areas, some mountainous locations have a cold climate. Tropical region occupant responses are unique in addressing mountain climate, in terms of either clothing items or activities. In tropical mountain areas, there are vernacular houses with either exposed stone walls or wooden walls. Vernacular houses are believed to be able to present as a comfortable residence.

The study was carried out in Wonosobo regency of Central Java province of Indonesia. Wonosobo is a region surrounded by some mountains. There are a variety of residences. Vernacular houses in Wonosobo comprise exposed stone houses and those with wooden walls. Most residences in Wonosobo feature zinc roof to anticipate cold climate. The study was conducted in a village located at the slope of the mountain at above $1000 \mathrm{~m}$ a.s.l. The average air temperature in the research location was $18-22^{\circ} \mathrm{C}$. In a certain time, the air temperature might reach $4^{\circ} \mathrm{C}$. The map of the research location is shown in Figure 1.

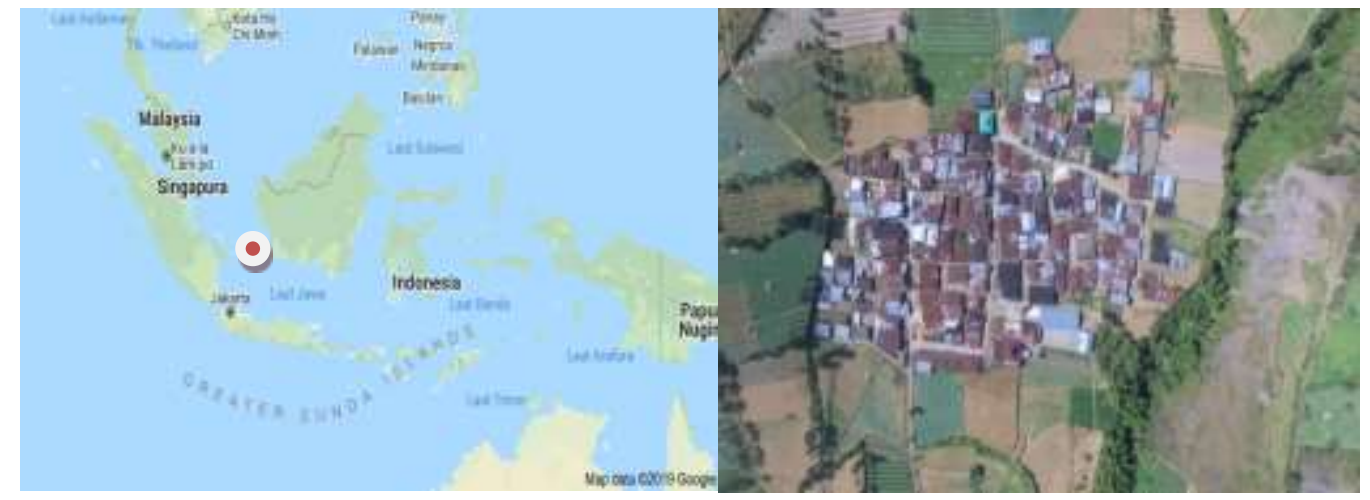

Fig. 1 Research location; (a)the map of Indonesia, (b)the village from above

The present study aims at comparing Thermal Sensation Vote (TSV) of occupants of exposed stone houses and those of wooden houses in mountainous locations to find out which houses providing comfort to the occupants. 


\section{MATERIALS AND METHOD}

The study was conducted in vernacular houses in mountainous locations. The vernacular houses have either exposed stone walls or wooden walls (Figure 2). Houses with exposed stone walls and those with wooden walls were determined according to the results of a pilot study on several types of houses in mountainous areas. The study was conducted in some mountainous areas around the province of Central Java, such as Mount Slamet, Mount Muria, Mount Sindoro, Mount Sumbing, and Mount Tidar. It resulted in the typology of vernacular houses with exposed stone walls and wooden walls.

The study was carried out on respondents who had complete family members, including father, mother, the first child, and the second child. The selection of the respondents was intended to find out the difference in thermal sensations according to a variety of ages and genders, and therefore various responses were revealed. These various responses would enrich the body of knowledge of adaptive thermal comfort based on human adaptation. The adaptive thermal comfort is also influenced by a variety of climates, and therefore the determination of seasons presents an important issue in the study. Indonesia is a country with two seasons, but in the transition period, it has a unique climate. The transition of seasons is known as a transitional season. The present study investigated the transitional season. The TSV comparison of the variety of ages and genders will lead to a conclusion on thermal comfort adaptation in each inhabitant. Adaptation is the core of the adaptive thermal comfort. The TSV comparison of the variety of ages and genders will strengthen the concepts of adaptation in adaptive thermal comfort.

The study was carried out in a one-year period divided into four seasonal periods: the beginning of the wet season, the middle of the wet season, the beginning of the dry season, and the middle of the dry season. Different seasons will contribute to different human responses [12]. The seasonal periods were carefully determined and a pilot survey by monitoring air temperature and humidity of survey locations in 15 consecutive days was conducted. When air temperature and humidity fitted to characteristics of the certain seasonal period, the survey was performed. A 5-day survey was performed in every seasonal period. The questionnaire was filled four times a day in the morning, afternoon, evening, and at night by respondents. The questionnaire was filled in at least three different periods of time [13].
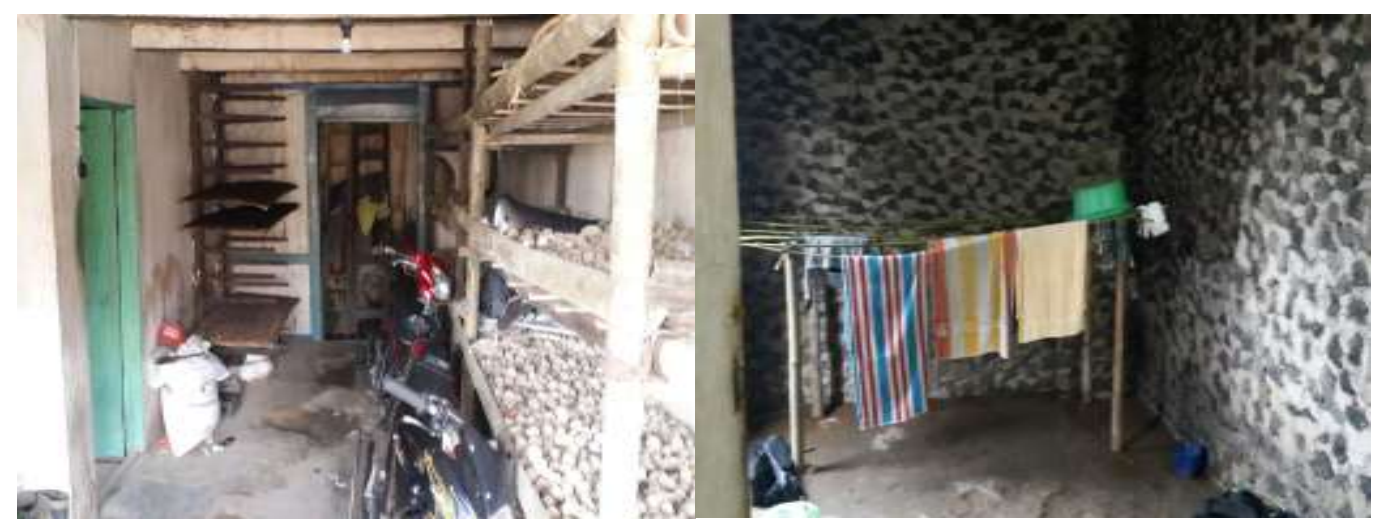

Fig. 2 (a) house with wood wall, (b) house with exposed stone wall

The number of TSV data was 2,228 comprising 1,078 data of TSV of occupants of exposed stone houses and 1,150 data of TSV of occupants of wooden houses. Table I demonstrates detailed information about the data. 
Table I. The Number Of Research Data

\begin{tabular}{|l|l|l|l|l|l|l|l|l|}
\hline \multirow{2}{*}{ Occupant } & \multicolumn{2}{l|}{$\begin{array}{l}\text { The Beginning Of } \\
\text { The Wet Season }\end{array}$} & \multicolumn{2}{l|}{$\begin{array}{l}\text { The Middle Of The } \\
\text { Wet Season }\end{array}$} & \multicolumn{2}{l|}{$\begin{array}{l}\text { The Beginning Of } \\
\text { The Dry Season }\end{array}$} & \multicolumn{2}{l|}{$\begin{array}{l}\text { The Middle Of The } \\
\text { Dry Season }\end{array}$} \\
\cline { 2 - 10 } & $\begin{array}{l}\text { Exposed } \\
\text { Stone } \\
\text { Houses }\end{array}$ & $\begin{array}{l}\text { Wooden } \\
\text { Houses }\end{array}$ & $\begin{array}{l}\text { Exposed } \\
\text { Stone } \\
\text { Houses }\end{array}$ & $\begin{array}{l}\text { Wooden } \\
\text { Houses }\end{array}$ & $\begin{array}{l}\text { Exposed } \\
\text { Stone } \\
\text { Houses }\end{array}$ & $\begin{array}{l}\text { Wooden } \\
\text { Houses }\end{array}$ & $\begin{array}{l}\text { Stone } \\
\text { Houses }\end{array}$ & $\begin{array}{l}\text { Wooden } \\
\text { Houses }\end{array}$ \\
\hline Fathers & 34 & 72 & 40 & 48 & 76 & 68 & 80 & 76 \\
\hline Mothers & 38 & 76 & 38 & 40 & 62 & 80 & 80 & 76 \\
\hline $\begin{array}{l}\text { The first } \\
\text { children }\end{array}$ & 38 & 44 & 34 & 44 & 72 & 61 & 80 & 60 \\
\hline $\begin{array}{l}\text { The } \\
\text { second } \\
\text { children }\end{array}$ & 30 & 44 & 30 & 36 & 66 & 72 & 80 & 53 \\
\hline Guests & 0 & 0 & 40 & 40 & 80 & 80 & 80 & 80 \\
\hline
\end{tabular}

The TSV was collected based on the ASHRAE 7-point scales of thermal sensation [14]. The analysis of the TSV comparison between the occupants of both types of houses and between the types of houses was shown in the diagram. Comparison analysis can be applied to find the results of the study [15].

\section{RESULTS AND DISCUSSION}

Most fathers voted for "slightly cool" during the four seasonal periods. The highest response rate of "slightly cool" in the dry season is about $45 \%$. Meanwhile, $5 \%$ of fathers voted for "hot" in the middle of the wet season at 5\% due to the sufficiently-hot condition of the environment. Fathers feel comfortable at the beginning of the wet season and in the middle of dry season at 20-25\%. The "very cold" condition is experienced by fathers in the middle of the wet season and at the beginning of the dry season. The highest "warm" response is experienced by fathers in the middle of the wet season. The highest "cold" response is experienced by fathers at the beginning of the dry season. The highest response on "slightly cool" indicates that fathers' body has adapted to cold temperature.

Similarly, most mothers voted for "slightly cool". Fewer mothers (below 10\%) feel hot in the middle of the wet season, at the beginning of the dry season, and during the dry season. In addition to "slightly cool", mothers tend to feel cold. The highest "cold" response at the beginning of the wet season is $40 \%$. Meanwhile, below $10 \%$ of mothers voted for "very cold", and $15 \%$ voted for "warm" on average in the four seasonal periods. The highest "warm" response is shown in the middle of the wet season. The middle of the wet season tends to have an adequately-high temperature at a certain time. The comfortable condition of mothers is not above $20 \%$. The "slightly cool" and "cold" responses demonstrate that women cannot stand cold temperature. The body adaptation to cold temperature has not occurred (Figure 3). 

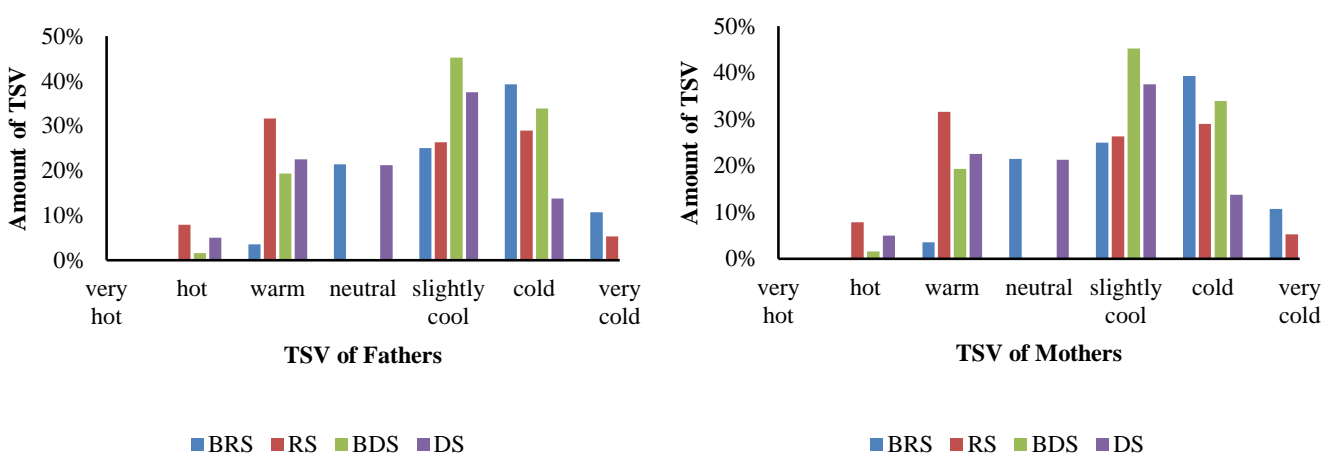

Fig. 3 Percentage of TSV of occupants of exposed stone houses in four seasonal periods:

(a)fathers; (b)mothers

\begin{tabular}{lllll}
\multicolumn{4}{c}{ Note } \\
BRS & $:$ Beginning of Rainy Season & BDS & $:$ Beginning of Dry Season \\
RS & $:$ Mid Rainy Season & DS & $:$ Mid Dry Season
\end{tabular}

Most first children correspondingly voted for "slightly cool". The second highest response is "cold". About $45 \%$ of the first children voted for "slightly cool" in three seasonal periods: the beginning of the wet season, the beginning of the dry season, and the middle of the dry season. The "slightly response" in the middle of the wet season is $20 \%$. The "cold" response is not higher than "slightly cool" response. The highest "cold" response is found in the middle of the wet season at nearly 50\%. The "very cold" response is not high at the beginning of the wet season, in the middle of the wet season, and at the beginning of the dry season. The first children do not feel very cold in the middle of the dry season. The "hot" sensation is felt in the middle of the wet season and the middle of the dry season. Similar to the above explanation, the "hot" response in the middle of the wet season and the middle of the dry season has resulted from the condition of the environment. Regarding the highest response ("slightly cool"), the first children do not feel cold. Body adaptation to cold temperature is found in the first children.

Different from other occupants, the second children frequently feel cold. However, the "cold" response rate is not far different from the "slightly cool" one. The average "cold" response rate in the four seasonal periods is about $35 \%$, while the average "slightly cool" response rate is about $30 \%$. Nevertheless, the striking difference occurs in "slightly cool" response. The highest "slightly cool" response is found at the beginning of the wet season. Meanwhile, the highest "cold" response occurs in the middle of the wet season. The second children's "very cold" response is found in three seasonal periods: the beginning of the wet season, the middle of the wet season, and the beginning of the dry season. The first children do not feel "very cold" sensation in the middle of the dry season. The second children do not feel comfortable in the middle of the wet season and the beginning of the dry season. The comfortable response of the second children is felt at the beginning of the wet season and in the middle of the dry season, but it is not in a large percentage (below 20\%). The second children feel "warm" in the middle of the wet season, at the beginning of the dry season, and in the middle of the dry season. The highest "hot" response is about $10 \%$. The response of the second children indicates the cold intolerance. Children have not yet had immunity, or still adapt to the cold condition (Figure 4). 

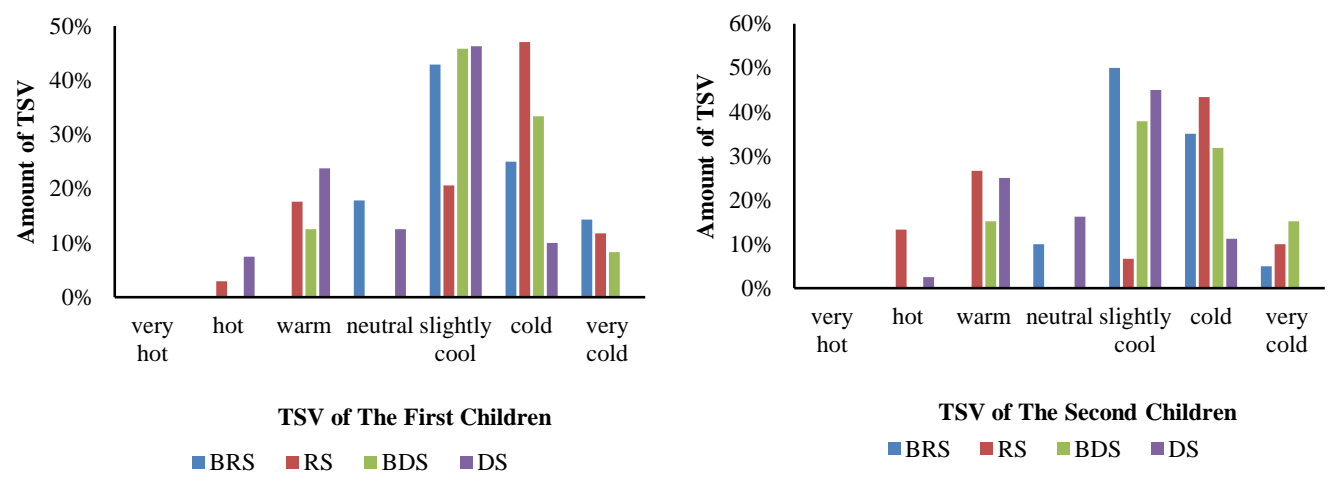

Fig. 4 Percentage of TSV of occupants of exposed stone houses in four seasonal periods:

(a) the first children; (b) the second children

No response at the beginning of the wet season is found in guest respondents. When the survey was conducted, no guest visited the house. Most guests feel cold in three seasonal periods: the middle of the wet season, the beginning of the dry season, the beginning of the dry season, and the middle of the dry season. They feel cold since they do not come from the region. The second highest response is "slightly cool". The "very cold" response only occurs in the middle of the wet season and beginning of the dry season at $20 \%$. The comfortable response is found in two seasonal periods: the middle of the wet season and dry season. At a certain time, guests feel comfortable in the middle of the wet season and dry season. Most guests feel warm in the middle of the dry season. In the middle of the wet season and the beginning of the dry season, guests feel warm at below 5\%. Both "warm" response and "hot" response are in the same percentage (below 5\%). Both responses emphasize that guests cannot adapt to cold temperature (Figure 5).

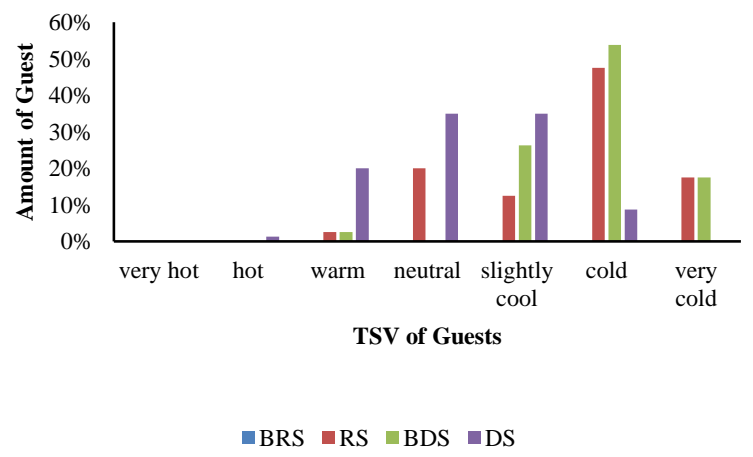

Fig. 5 Percentage of TSV of guest respondents of exposed stone houses in four seasonal periods

Most fathers voted for "slightly cool" and "cold", but "slightly cool" response (35\%) is the higher than "cold" response (30\%). Fathers feel very cold and hot only at the beginning of the wet season. The "very cold" response rate is higher than the "hot" response one. Fathers feel warm in all seasonal periods on average at $15 \%$. They feel comfortable in the middle of the wet season at $20 \%$. At the beginning of the wet season and in the middle of the dry season, fathers feel comfortable at no more than 5\%. The three highest responses demonstrate an extreme environment. Fathers' comfortable response does not belong to the three categories. Fathers feel slightly cool and cold, but at a certain time they feel warm. The comfortable response does not occur in them.

Similarly, most mothers voted for "slightly cool". The average "slightly cool" sensation in the four seasonal periods is nearly $40 \%$, while the average "cold" sensation is $30 \%$. The 
"very cold" sensation is felt in the two seasonal periods: the beginning of the wet season and the beginning of the dry season. Meanwhile, "hot" sensation is felt at the beginning of the wet season at below 5\%. The highest comfortable or neutral sensation occurs in the middle of the wet season. In the middle of the dry season, mothers do not feel comfortable. Such condition is similar to that experienced by fathers. The "warm" sensation rate approaches the "cold" sensation rate. Mothers feel different warm sensations in the four seasonal periods. The highest "warm" sensation rate occurs in the middle of the dry season (Figure 6).

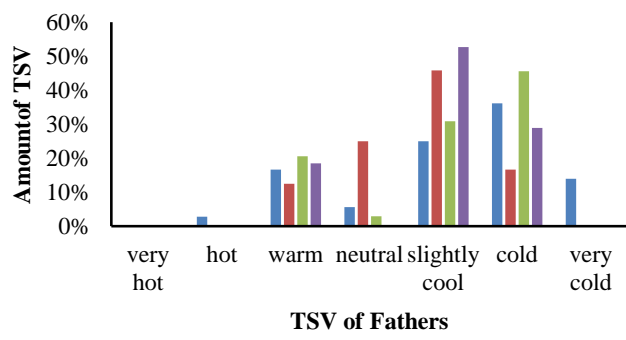

$\because \mathrm{BRS} \square \mathrm{RS}=\mathrm{BDS} \approx \mathrm{DS}$

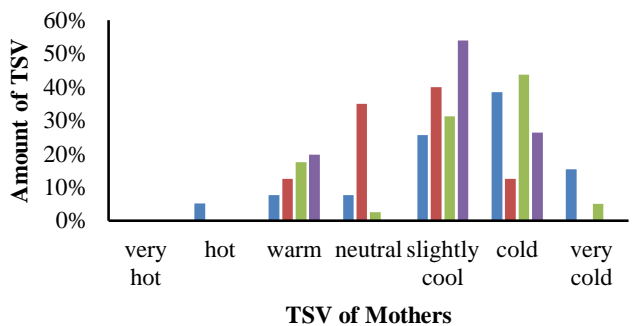

$\because \mathrm{BRS} \backsim \mathrm{RS} \backsim \mathrm{BDS} \backsim \mathrm{DS}$

Fig. 6 Percentage of TSV of occupants of wooden houses in four seasonal periods: (a) fathers; (b) mothers

The distribution of "slightly cool" response and "cold" response of the first children is not far different. The "slightly cool" response occurs on average at $40 \%$, while the "cold" response occurs at $35 \%$. The highest response rate of the first children is "slightly cool". The first children did not give high response to "warm" response (below 10\%). Both "neutral" and "very cold" responses indicate adequately-high response in the middle of the wet season and the beginning of the wet season. In other seasonal periods, the existing responses are not very high. Both highest responses ("slightly cool" and "cold") indicate that the first children are less adaptable to cold temperature.

There is a striking difference between "slightly cool" response and "cold" response of the second children. More second children feel "cold" than "slightly cool". The average "slightly cool" response is about $30 \%$, while the average "cold" response is $40 \%$. The striking difference is seen at the beginning of the wet season in which "slightly cool" response is far different from "cold" response. The "slightly cool" response appears at below $10 \%$, while the "cold" response appears at above $50 \%$. Such difference occurring at the beginning of the wet season is in accordance with the low temperature of the environment.

There is no striking difference between the "very cold" response and "hot" response. Both responses only appear at below $10 \%$ at the beginning of the wet season, in the middle of the wet season, and at the beginning of the dry season. The "warm" response appears in the four seasonal periods, but there is a striking difference between at the beginning of the wet season and in the middle of the dry season. In the middle of the wet season and the beginning of the dry season, the response is below 5\%. The "neutral" response rate on average is not high. Only in the middle of the wet season, the second children feel comfortable at about $20 \%$. Such uncomfortable condition and the low "warm" response rate indicate that the second children have not yet been adaptable to cold temperature. Adaptation is influenced by the age of the second children (Figure 7). 

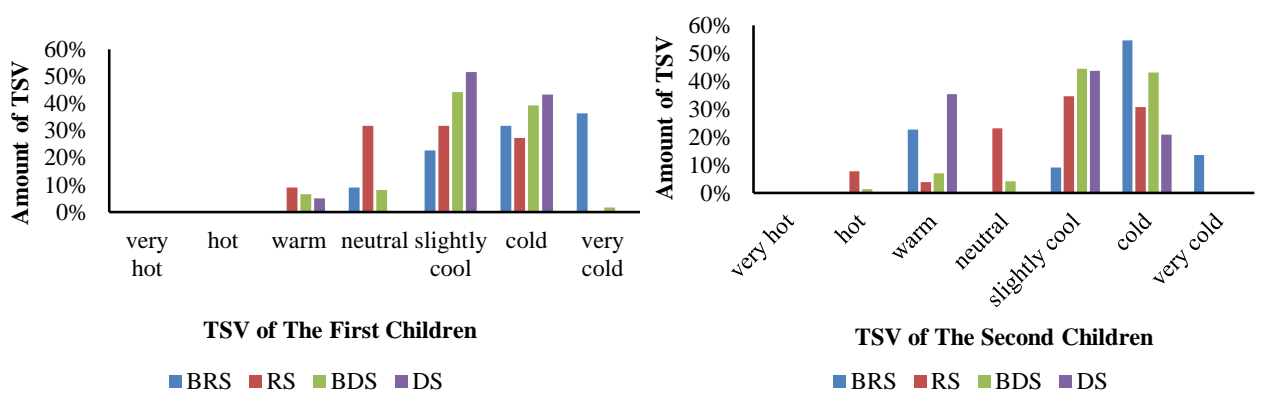

Fig. 7 Percentage of TSV of occupants of wooden houses in four seasonal periods: (a) the first children; (b) the second children

Similar to survey results on guests of exposed stone houses, the survey results on guests of wooden houses find out that there is no guest visiting the house at the beginning of the wet season. The "cold" response is high in the three seasonal periods. The average "cold" response is $50 \%$. The "cold" response and the "slightly cool" response have a percentage difference of $20 \%$. The "slightly cool" response is evenly distributed in the three seasonal periods at 30\%. Guests feel very cold, warm, and neutral (below 5\%). The highest response is the "cold" response, meaning that guests do not adapt to cold temperature since they do not come from the region (Figure 8).

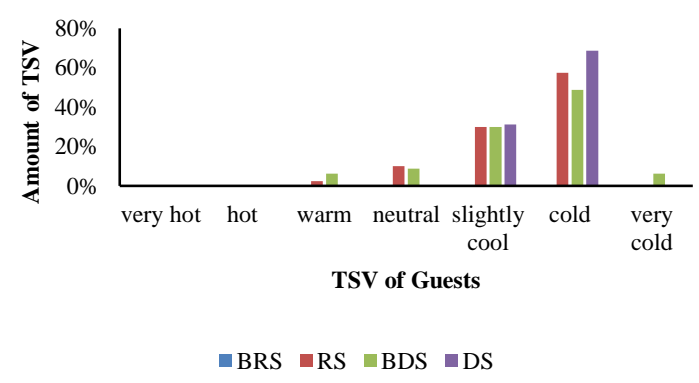

Fig. 8 Percentage of TSV of guest respondents of wooden houses in four seasonal periods

Data of exposed stone houses and wooden houses in each seasonal period are shown below. The highest response of fathers living in exposed stone houses and in those with wooden walls at the beginning of the wet season is "cold" (35\%). On "slightly cool" response, fathers living in exposed stone houses gave more votes than fathers living in wooden houses. The percentage difference is $10 \%$. On "neutral" response, fathers living in exposed stone houses gave more votes $(15 \%)$ than fathers living in wooden houses. On "warm" response, fathers living in wooden houses gave more votes than fathers living in exposed stone houses. On "very cold" and "hot" responses, fathers living in wooden houses gave the votes. The responses seem to be evenly distributed. The "very hot" sensation is felt by fathers living in wooden houses. Fathers living in exposed stone houses responded to four sensations: "warm", "neutral", "slightly cool", and "cold". The dominant response of fathers living in both types of houses is "cold". The "neutral" condition appears due to age factor; fathers living in exposed stone houses are younger than fathers living in wooden houses.

At the beginning of the wet season, mothers shared similar responses: "warm", "slightly cool", "cold", and "very cold". On "neutral" condition, mothers living in exposed stone houses gave more votes. The percentage difference is $15 \%$. Below $5 \%$ of mothers living in wooden houses feel hot. Mothers living in wooden houses are older than mothers living in 
exposed stone houses. The thermal adaptation of mothers living in exposed stone houses to cold is better. Mothers living in wooden houses feel warmer than mothers living in exposed stone houses. Such conditions occur due to a warmer atmosphere of wooden houses. However, the absence of "neutral" sensation in mothers living in wooden houses indicates the great fluctuation of the thermal condition of wooden houses (Figure 9).
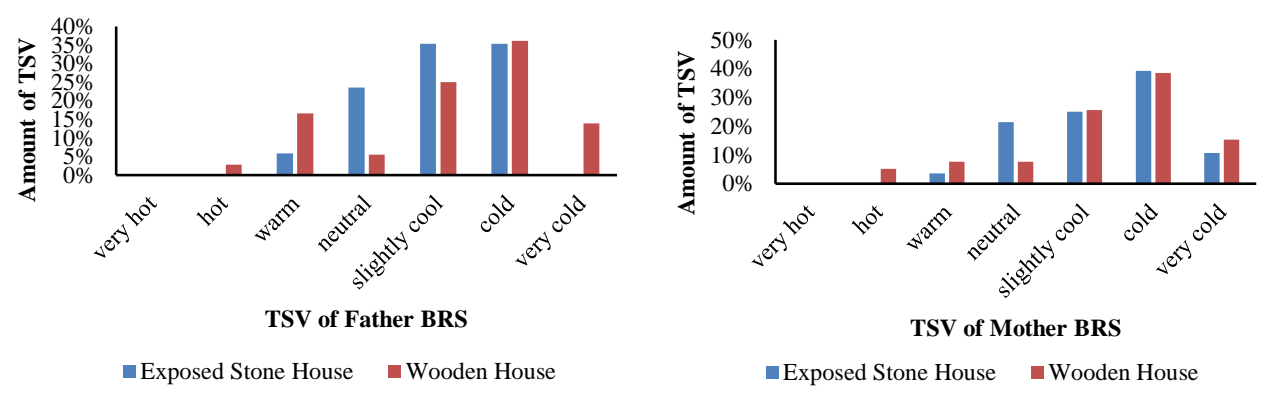

Fig. 9 TSV percentage at the beginning of the wet season: (a) fathers; (b) mothers

At the beginning of the wet season, the first children living in exposed stone houses and in wooden houses voted for "neutral", "slightly cool", "cold", and "very cold". The four responses are not similar. On "slightly cool" response, the first children living in exposed stone houses gave more votes than those living in wooden houses with a percentage difference of about $20 \%$. In addition, on "neutral" response the first children living in exposed stone houses gave more votes with a percentage difference of about $10 \%$. On "cold" and "very cold" responses, the second children living in exposed stone houses gave fewer votes than the second children living in wooden houses. The response difference reveals a higher "extremely cold" response of the first children living in wooden houses.

There is a percentage difference between the response of the second children living in exposed stone houses and those living in wooden houses. On "slightly cool" response, the second children living in exposed stone houses gave more votes than those living in wooden houses with a percentage difference of $40 \%$. On "cold" and "very cold" responses, the second children living in exposed stone houses gave fewer votes than those living in wooden houses. On "warm" response, the second children living in wooden houses gave the votes and on "neutral" response the second children living in exposed stone houses gave the votes. The distribution of responses of the second children appears due to a large age gap. Different ages will contribute to different responses (Figure 10).
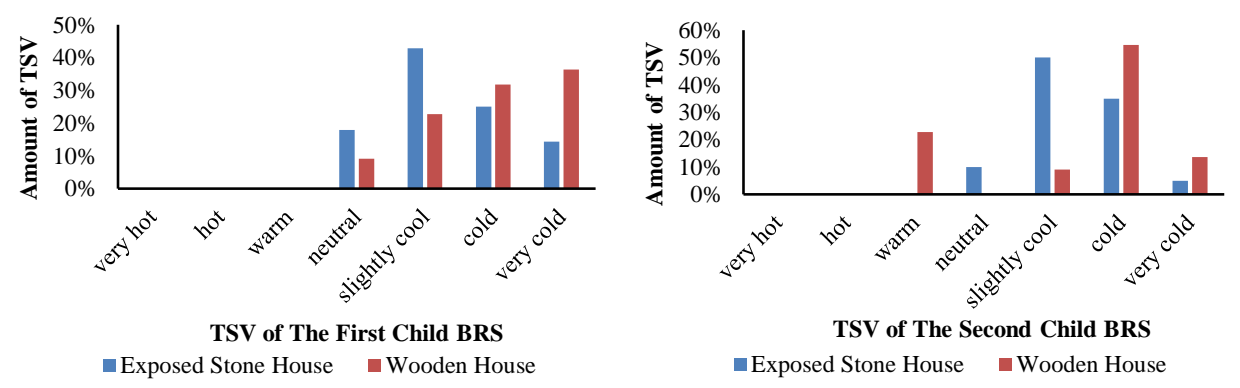

Fig. 10 Percentage of TSV at the beginning of the wet season: (a) the first children; (b) the second children

The responses of the first children living in exposed stone houses in the middle of the wet season include "hot", "warm", "slightly cool", "cold", and "very cold". The first 
children living in wooden houses voted for "warm", "neutral", "slightly cool", and "cold". On "warm" and "cold" responses, the first children living in exposed stone houses gave more votes, with percentage difference of $10-20 \%$. On "slightly cool" response, the first children living in exposed stone houses gave more votes, with percentage difference of $10 \%$. The response difference appears due to a fluctuated air temperature of exposed stone houses.

The second children voted for three responses of which percentage is higher in those living in exposed stone houses with the greatest percentage difference in "warm" response (about 25\%). The second children living in exposed stone houses gave a response of 30\%, while the second children living in wooden houses gave a response of $5 \%$. The response of the second children living in exposed stone houses is similar to that of the first children living in both exposed stone houses and wooden houses. The difference is on the "slightly hot" sensation experienced by the second children due to their inability to adapt to cold (because of their younger age) (Figure 11).
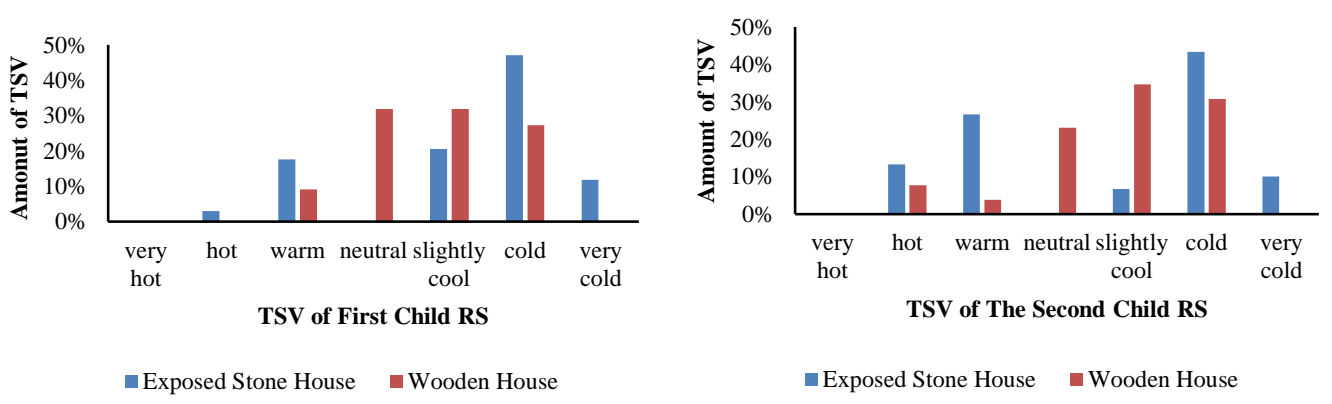

Fig. 11 Percentage of TSV in the middle of wet season: (a) the first children, (b) the second children

At the beginning of the dry season, the responses of fathers living in exposed stone houses and those living in wooden houses share a similarity. On "warm", "cold", and "slightly cool" responses, the percentage difference of responses of fathers living in both types of houses is not very large. Meanwhile, the difference is seen on "neutral" condition. Fathers living in wooden houses gave a "neutral" response at below 5\%, while fathers living in exposed stone houses do not feel "neutral" condition. Fathers living in exposed stone houses feel "very cold" sensation, while fathers living in wooden houses do not.

Mothers' responses are not far different from fathers' in the dry season: "warm", "slightly cool", and "cold". The percentage differences vary from $2 \%$ to $10 \%$. On "slightly cool" response, mothers living in exposed stone houses gave more votes. However, on "cold" response, mothers living in exposed stone houses gave fewer votes. Such nonlinear comparison is influenced by different activities in dry season performed by mothers living in exposed stone houses and those living in wooden houses (Figure 12).
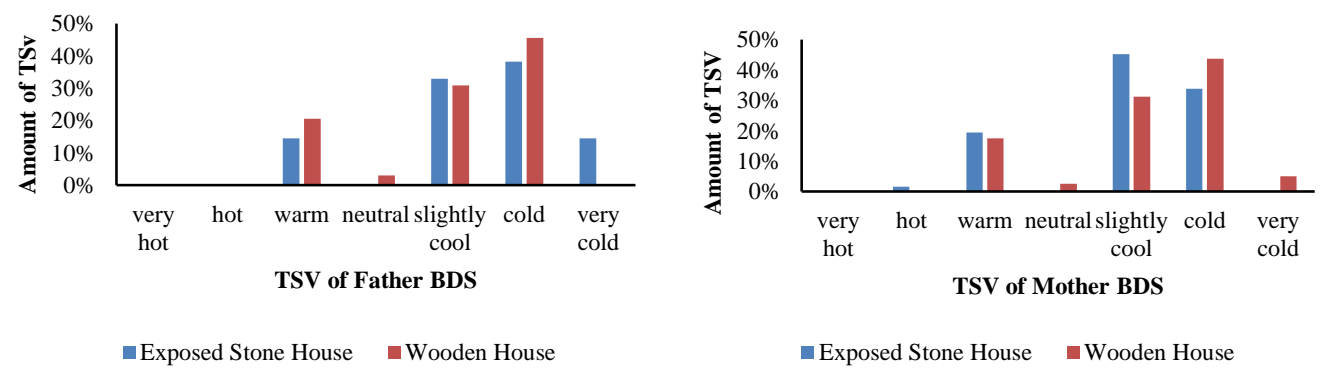

Fig. 12 Percentage of TSV at the beginning of the dry season: (a) fathers; (b) mothers 
There is not much difference in responses of the first children living in exposed stone houses and those living in wooden houses at the beginning of the dry season. The first children living in both types of houses voted for "warm", "slightly cool", "cold", and "very cold". The "neutral" response is the only different response. The "neutral" sensation is felt by the first children living in wooden houses (not at below 10\%). The response is in accordance with the fact that the age and the gender of the children are alike.

The response of the second children at the beginning of the dry season seems to be slightly different. There are two responses found to share a similarity in percentage: "slightly cool: and "cold". On the two responses, the second children living in exposed stone houses gave fewer votes. Meanwhile, on "warm" response, the second children living in exposed stone houses gave more votes than the second children living in wooden houses with a percentage difference of $7 \%$ (Figure 13).

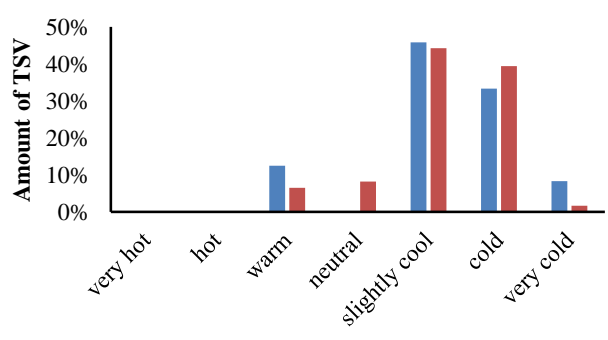

TSV of First Child BDS

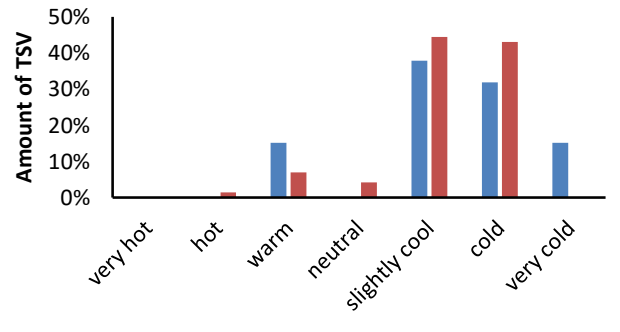

TSV of Second Child BDS

- Exposed Stone House $\quad$ Wooden House

Fig. 13 Percentage of TSV at the beginning of the dry season: (a) the first children; (b) the second children

In the dry season, "warm" and "slightly cool" responses of fathers living in exposed stone houses and those of fathers living in wooden houses are not far different. "Neutral" response is only felt by fathers living in exposed stone houses. The "cold" sensation is higher in fathers living in wooden houses. In the dry season, fathers do not feel "extreme" sensations such as very cold, very hot, and hot. The condition which approximates "extreme" is the "cold" response. Mothers' responses in the dry season are not far different. Three thermal sensations are found: "warm", "slightly cool", and "cold". The greatest difference among the three thermal sensations is $10 \%$ occurring in "slightly cool" response. Mothers living in exposed stone houses feel "neutral" and "hot" sensations, while mothers living in wooden houses do not (Figure 14).
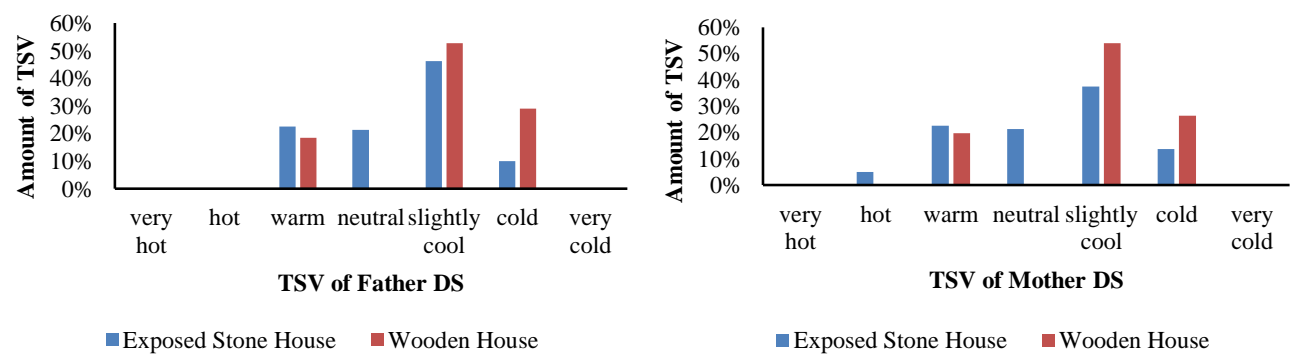

Fig. 14 Percentage of TSV in the middle of the dry season: (a) fathers; (b) mothers

In the middle of the dry season, the first children living in exposed stone houses and those living in wooden houses share a similarity in "slightly cool" response with a percentage difference of below 5\%. However, on "cold" response, there is a striking difference: a response rate of the second children living in exposed stone houses is lower 
than that of the second children living in wooden houses with a percentage difference of $30 \%$. In the middle of the dry season, the responses of occupants of exposed stone houses are more evenly distributed. The first children living in exposed stone houses feel neutral.

Responses of the second children are not far different from those of the first children, except "warm" response. The responses of the second children living in exposed stone houses are lower than those of the second children living in wooden houses with a percentage difference of $10 \%$. On "slightly cool" response, the percentage difference is below $5 \%$, while on "cold" response, the percentage difference is $10 \%$. In addition, the second children living in exposed stone houses feel "hot" and "neutral" sensations, while the second children living in wooden houses do not (Figure 15).
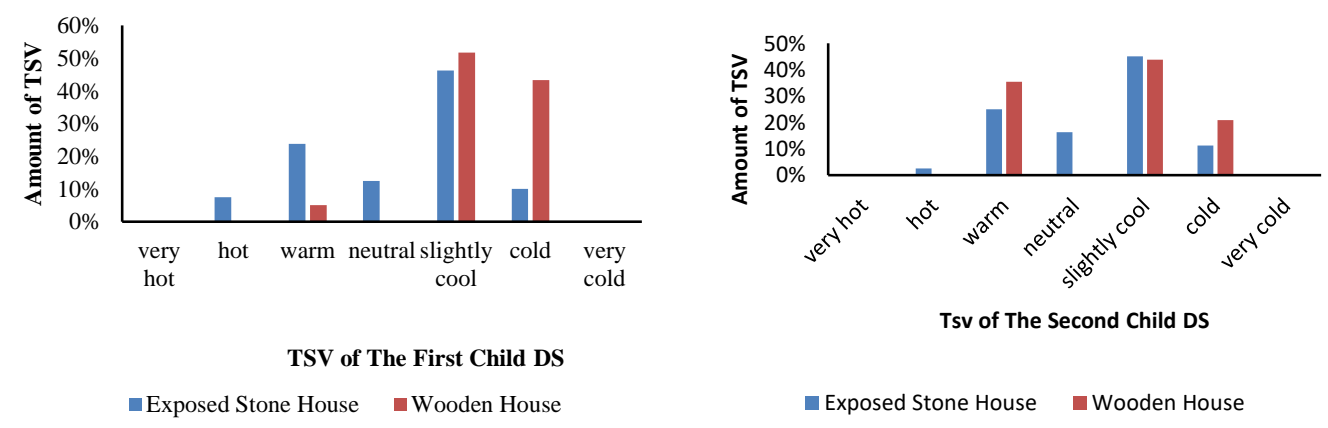

Fig. 15 Percentage of TSV in the middle of the dry season: (a) the first children; (b) the second children

Guests of both exposed stone houses and wooden houses tend to give "cold" response at the beginning of the wet season and in the middle of the wet season. At the beginning of the wet season, exposed stone houses tend to have a lack of capacity in responding to the thermal environment. On "neutral" response, guests of exposed stone houses feel more comfortable than those of wooden houses. In the middle of the wet season, "neutral" sensation is felt in wooden houses, but it does not contribute to a high percentage (Figure 16).
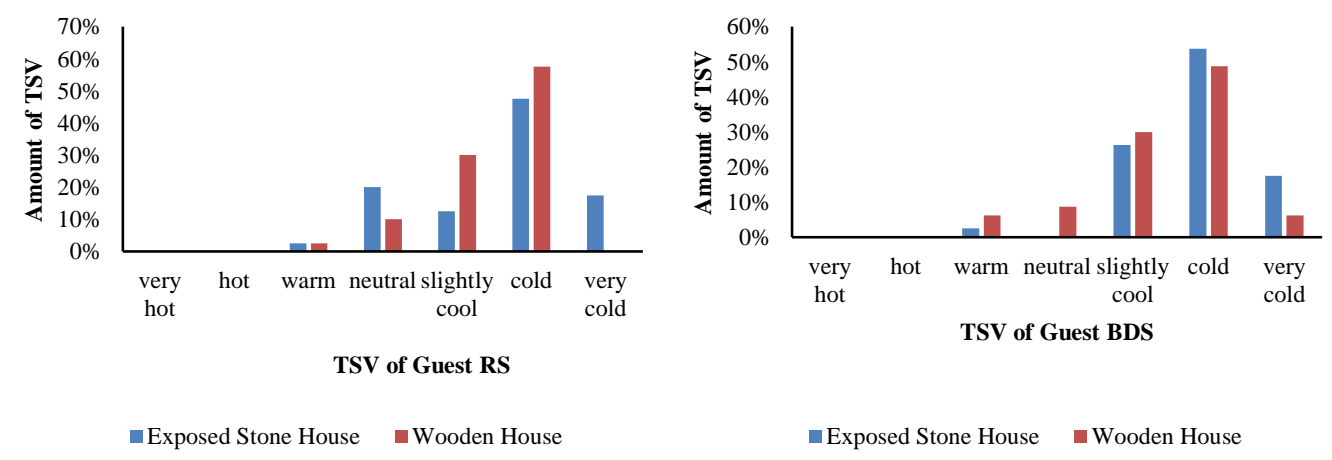

Fig. 16 Percentage of TSV of guests: (a) at the beginning of the wet season; (b) in the middle of the wet season

The middle of the dry season reveals the comfortable response of guests of exposed stone houses. In wooden houses, the highest response is the "cold" response, with a percentage difference of $60 \%$. On "slightly cool" response, guests of exposed stone houses and those of wooden houses share similarity since the percentage difference is only $3 \%$. The "warm" condition is felt by guests of exposed stone houses. In the dry season, exposed stone houses are considered to be more comfortable. 
The human response depends on the time required to adapt. The longer humans adapt at a certain place, the better they are able to adapt to their environment [16]. Human character of being adaptable influences thermal comfort created to occupants of both exposed stone houses and wooden houses. Besides the occupants, the respondents also include those who do not come from the region. The different responses are in accordance with the results of other studies which reveal that adaptation presents as influencing factor in human thermal sensation. In addition to the adaptation to the environment, age and gender also serve as influencing factors in response to climate [17].

Age becomes the influencing factor since age difference will exert an influence on the difference of human skin surface area and longer time for adaptation. A response experienced by humans is a response to the climate variable to which the human skin surface is exposed. In addition to age, gender also presents as the influencing factor due to the presence of human body mass. Body mass will influence human response to thermal environment [18]. The results of the study indicate that different ages are distributed in exposed stone houses, and consequently different responses are obtained. The age of the first children and the second children living in wooden houses is not far different, and therefore there are not many different responses. In addition, both children have the same gender (male). The unacceptable thermal condition will result in hampered activities [19]. Occupants of vernacular houses in mountainous areas use a fireplace, or so-called genen, to adapt to the thermal environmental conditions. The fireplace is used in the morning and evening to ease humans in doing their activities [20]. Genen has been used for a long period of time.

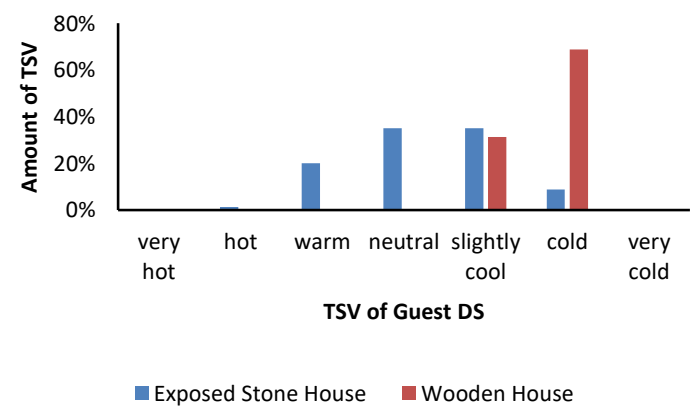

Fig. 17 Percentage of TSV of guests in the middle of the dry season

Occupants of both exposed stone houses and wooden houses share similar responses: "hot", "warm", "neutral", "slightly cool", "cold", and "very cold". On "hot", "warm", "neutral", and "very hot" conditions, occupants of exposed stone houses gave higher response than occupants of wooden houses with percentage difference from $2 \%$ to $10 \%$. Higher "neutral" response indicates that occupants of exposed stone houses feel more comfortable than occupants of wooden houses. On "slightly cool" and "cold" conditions, occupants of exposed stone houses gave a lower response than occupants of wooden houses. This emphasizes that occupants of exposed stone houses do not feel slightly cool and cold. However, on "very cold" condition, occupants of exposed stone houses gave higher response than occupants of wooden houses. This is possibly due to a very cold sensation at the cold temperature given by exposed stone houses. The material properties of stones will contribute to cols sensation at cold temperature. Nevertheless, the stone wall propagation cannot immediately be seen from lower occupants' "slightly cool" and "cold" responses. The difference in building materials will result in different thermal environments for the occupants. Wooden materials are considered to be suitable for coastal areas instead of mountainous areas. Prior studies which compared occupants' comfort reveal that occupants of wooden houses in feel more comfortable than occupants of wooden 
houses in mountainous areas [21]. Stones are concrete materials and are considered to be able to protect from the cold climate. Stones are solid materials which contribute to energy efficiency [22].

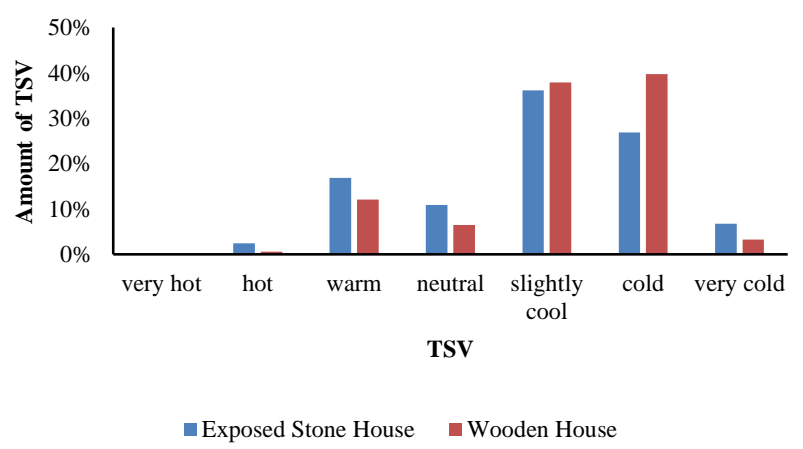

Fig. 18 The comparison of thermal sensations of all occupants in four seasonal periods

\section{CONCLUSION}

Thermal Sensation Vote (TSV) on vernacular houses in mountainous areas shows different results from other studies. The influence of age, gender, body mass, and body surface area on TSV is found in the study. Responses of occupants of both exposed stone houses and those with wooden walls seem similar, but in fact, vary. Seen from the materials of walls, exposed stone houses are able to give higher comfort than wooden houses. On "very cold" condition, occupants of exposed stone houses gave higher response due to the fact that the material properties of stones can maintain cold temperature for a longer period of time. The "very cold" response should be clarified in future research. It is expected that the building materials can be created to establish thermal comfort of occupants in mountainous areas.

\section{ACKNOWLEDGMENTS}

Thanks to architecture department of Qur'anic Science University for supporting this research.

\section{REFERENCES}

[1] Koelblen B., Psikuta A., Bogdan A., Annaheim S., Rossi René M., "Human simulator - A tool for predicting thermal sensation in the built environment”, Building and Environment, 143, (2018), pp. 632644.

[2] Broday, Evandro Eduardo, Moreto, Jeferson Aparecido, Xavier, Antonio Augusto de Paula, de Oliveira, Reginaldo, "The approximation between thermal sensation votes (TSV) and predictedmean vote (PMV): A comparative analysis", International Journal of Industrial Ergonomics 69 (2019), pp. 1-8.

[3] Cheng, Chin-Chi, Lee, Dashang, Huang, Bi-Song, "Estimated thermal sensation models by physiological parameters during wind chill stimulation in the indoor environment", Energy \& Buildings 172 (2018), pp. 337-348.

[4] Perez-Fargallo, J.A., Pulido-Arcas, C., Rubio-Bellido, M., Trebilcock, B., Piderit, S., Attia, "Development of a new adaptive comfort model for low income housing in the central-south of Chile", Energy \& Buildings 178, (2018), pp. 94-106.

[5] Lima, Jongyeon, Akashia, Yasunori, Song, Doosam, Hwang, Hyokeun, Kuwaharad, Yasuhiro, Yamamura, Shinji, Yoshimoto, Naoki, Itahashi, Kazuo, "Hierarchical Bayesian modeling for predicting ordinal responses of personalized thermal sensation: Application to outdoor thermal sensation data", Building and Environment, 142, (2018), pp. 414-426.

[6] Cóstola, D., Carreira, G., Fernandes, L.O., Labaki, L.C., "Seasonal thermal sensation vote-an indicator for long-term energy performance of dwellings with no HVAC systems", Energy \& Buildings, 187, (2019), pp. 64-76. 
[7] Kim, Minjung, Chong, Sang Chul, Chun, Chungyoon, Choi, Yoorim, "Effect of thermal sensation on emotional responses as measured through brain waves", Building and Environment, 118 (2017), pp. 3239.

[8] Han, Dianshan, Li, Rui, Wang, Fulin, Suna, Zeyu, Moon, Saejin, Gong, Ziyang, Yu, Wenhong, Yin, Zhang, "Study on indoor thermal environment control based on thermal sensation prediction", 205 (2017): 3072-3079.

[9] Calis, Gulben \& Kuru, Merve, “Assessing user thermal sensation in the aegean region against standards", Sustainable Cities and Society, 29, (2017), pp. 77-85.

[10] Hadianpour, Mohammad, Mahdavinejad, Mohammadjavad, Bemanian, Mohammadreza \& Nasrollahi, Farshad, "Seasonal differences of subjective thermal sensation and neutral temperature in an outdoor shaded space in Tehran, Iran", Sustainable Cities and Society 39, (2018), pp. 751-764.

[11] Koelblen, Barbara, Psikuta, Agnes, Bogdan, Anna, Annaheim, Simon, Rossi, René M., "Thermal sensation models: validation and sensitivity towards thermo-physiological parameters", Building and Environment, (2018), pp. 200-211.

[12] Vellei, M., Natarajan, S., Biri, B. Padget, J., Walker, I., "The effect of real-time context-aware feedback on occupants' heating behaviour and thermal adaptation”, Energy and Buildings, 123 (2016), pp. 179191.

[13] Gallardo, A., Palme, M., Lobato-Cordero, A., Beltrán, R.D., Gaona, G. "Evaluating thermal comfort in a naturally conditioned office in a temperate climate zone", Buildings, 6.27, (2016).

[14] Xu, C., Li, S., Zhang, X., Shao, S., "Thermal comfort and thermal adaptive behaviours in traditional dwellings: a case study in nanjing, China", Building and Environment, 142, (2018), pp. 153-170.

[15] Yao, J., Yang, F., Zhuang, Z., Shao, Y., Yuan. P.F., "The effect of personal and microclimatic variables on outdoor thermal comfort: a field study in a cold season in Lujiazui CBD, Shanghai", Sustainable Cities and Society, 39 (2018): 181-188.

[16] Li, Yong, Geng, Shibin, Chena, Fei, Li, Chaofeng, Zhang, Xiaosong, Dong, Xian. "Evaluation of thermal sensation among customers: results from field investigations in underground malls during summer in Nanjing, China", Building and Environment 136 (2018), pp. 28-37.

[17] Maykot, Jéssica Kuntz, Rupp, Ricardo Forgiarini, Ghisi, Enedir. "A field study about gender and thermal comfort temperatures in office buildings", Energy and Buildings, 178, (2018), pp. 254-264.

[18] Joon-Ho, Choi, Yeom, Dongwoo, "Investigation of the relationships between thermal sensations of local body areas and the whole body in an indoor built environment", Energy and Buildings, 147 (2017): 204215.

[19] Derks, M. T. H., Mishra, A. K., Loomans, M. G. L. C., Kort, H. S. M., "Understanding thermal comfort perception of nurses in a hospital ward work environment", Building and Environment, 140 (2018), pp. 119-127.

[20] Hermawan and Prianto, Eddy. "Thermal evaluation for exposed stone house with quantitative and qualitative approach in mountainous area, Wonosobo, Indonesia”, IOP Conf. Ser.: Earth Environ. Sci.99 (2017): 012017.

[21] Hermawan, Prianto, Eddy, Setyowati, Erni. "Thermal comfort of wood-wall house in coastal and mountainous region in tropical area”, vol. 125, (2015), pp. 725-731.

[22] English Heritage, Energy Efficiency In Historic Buildings, Insulating solid walls, English Heritage: 2010. 
International Journal of Advanced Science and Technology Vol.130 (2019) 